Centre, Keele University, Staffordshire, ST5 5BG.

E-mail: c.d.mallen@cphc.keele.ac.uk

\section{George Peat}

Senior Lecturer in Clinical Epidemiology, Arthritis Research Campaign,

Keele University.

\section{REFERENCES}

1. Mallen CD, Peat G. Screening older people with musculoskeletal pain for depressive symptoms in primary care. Br J Gen Pract 2008; 58(555): 688-693.

2. Zigmond AS, Snaith RP. The hospital anxiety and depression scale. Acta Psychiatr Scand 1983; 67(6): 361-370.

3. Mallen CD, Peat G, Thomas E, et al. A systematic review of prognostic factors for joint pain in primary care: a systematic review. Br J Gen Pract 2007; 57(541): 655-661.

DOI: 10.3399/bjgp09X394888

\section{The end of practice-based research?}

Recently, McWhinney ${ }^{1}$ has stated that there is little being published in the journals of family medicine and general practice concerning clinical insight and discovery. In particular, he has deplored the lack of clinical research carried out by single practitioners working with their own patients. As one who first joined the Royal College of General Practitioners in 1968, I was interested to discover whether this criticism applied to the $B J G P$ and whether the approach to the publication of research had changed over 40 years. I therefore surveyed the journal over 6-months from January to June 2008 and compared the research content with that published in the same months of 1968. I was careful to exclude reviews and lectures (Table 1).

It would appear that the combination of working GP and researcher has become extinct. Even if this is not the case, it is fairly obvious that the locus of research has shifted fundamentally from the individual practitioner to the large research team and from the particulars of individual practice to the generalities of large populations. Doubtless this approach has led to the acceptance of

Table 1. A comparison of research studies published in 6-month periods in 1968 and 2008.

\begin{tabular}{ccccc} 
Year & Studies & Authors $(n /$ study) & Practice-based $(\%)^{\mathrm{a}}$ & GP author $(\%)^{\mathrm{b}}$ \\
\hline 1968 & 31 & $36(1.2)$ & $26(84)$ & $28(78)$ \\
\hline 2008 & 35 & $208(5.1)$ & $0(0)$ & $0(0)$ \\
\hline
\end{tabular}

${ }^{a}$ Research studies carried out in the author's practice. ${ }^{b}$ First author was a working GP.

the discipline of general practice in the wider academic and research community, but the role of the GP seems to have changed from being the investigator to the investigated, and from being the initiator of questions, to being a source of access to the questions of academics from our own and other disciplines.

McWhinney's view is that clinical discovery is essential and 'can be done only by clinicians working with their patients,' so by definition this finding does not augur well for the future of our discipline. He believes that there must be a place for clinicians' observations, hunches, and insights in family medicine and general practice journals. Manifestly, there is no place for this within the current journal and we need such a place - an appropriate mid-point between what is now regarded as a rigorous research paper and the pseudointellectual chatterings that occupy the 'Back Pages.'

There is little doubt in my mind that, if Dr William Pickles of Aysgarth ${ }^{2}$ were to submit a manuscript entitled 'An outbreak of catarrhal jaundice' to any modern journal, it would be rejected. How would they confirm as evidencebased, the statement 'S. P., page 32, who began with jaundice on August 24th, and who sold sweets in the village shop?' In his world, the world of real general practice, the input of the patient was critical because their meanings could be helpful. As he wrote elsewhere, ${ }^{3}$ 'Country beliefs may be helpful, and should not be cursorily ignored.

Classically the world gained much when Edward Jenner listened to one of these, and solved the riddle of the milkmaid's flawless cheek.'

McWhinney writes, 'If information is gained only from questionnaires, and the investigator has no contact with the patient, he has to interpret the words himself without gathering the patient's meaning in the course of a dialogue. This is not a rigorous procedure."1 The disappearance of the personal researcher does it improve our discipline? As Marinker ${ }^{4}$ succinctly put it, 'At the centre of general practice is the encounter between the doctor and the patient. If we fail to value the uniqueness of the doctor and the patient, the role of feelings and situations in the interpretation of symptoms and findings, we are condemned to be second rate players in a second hand game.'

\section{John Campbell Murdoch}

Professor, University of Western Australia, Rural Clinical School, 19 Driver Road, Dalyellup, 6230, Australia.

E-mail: campbell.murdoch@uwa.edu.au

\section{REFERENCES}

1. McWhinney IR. Assessing clinical discoveries. Ann Fam Med 2008; 6(1): 3-5.

2. Pickles WN. Epidemic catarrhal jaundice. An outbreak in Yorkshire. BMJ 1930; 1: 944-946.

3. Pickles WN. Epidemiology in country practice. Proc $R$ Soc Med 1935; 28(10): 1337-1342.

4. Marinker M. Journey to the interior: the search for academic general practice. J R Coll Gen Pract 1987; 37(302): 385-388.

DOI: 10.3399/bjgp09X394897 